\title{
Scientific publications: A key factor of the European research area
}

Presented by Nicole Dewandre

European Commission Research Directorate General, Scientific Advice and Governance, Brussels, Belgium

Report from the editors

\section{Introduction}

Academic publishing is at the heart of the European Research area was Mrs Dewandres' main message and the essence of what she had to say.

A staff member of the European Commission for many years, she moved to the science publishing area only recently. She was therefore interested to listen to the conference debates. She claimed that this reflected the attitude of Commissioner Potočnik with respect to science publishing ${ }^{1}$.

The Commission published the result of a study that was commissioned in June $2004^{2}$. This study is the basis of a public consultation lasting until June 1st. Thereafter a conference will be organised to take stock of the comments received. This result of the study and the recommendations of the authors were the core of her presentation.

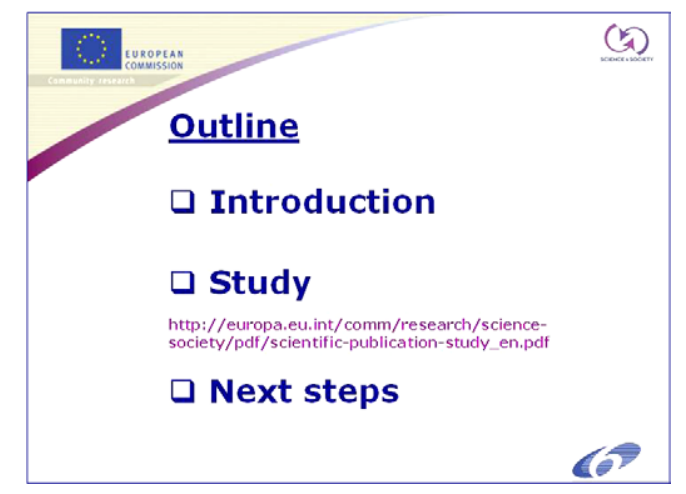

\footnotetext{
${ }^{1} \mathrm{Mr}$ Potočnik is responsible for research in the European Commission, and in this capacity for the involvement of the Commission with science publishing.

${ }^{2}$ The report can be downloaded from the website: http://europa.eu.int/comm/research/science-society/pdf/scientificpublication-study_en.pdf.
} 


\section{Publishing for the European Research Area and the Lisbon Strategy}

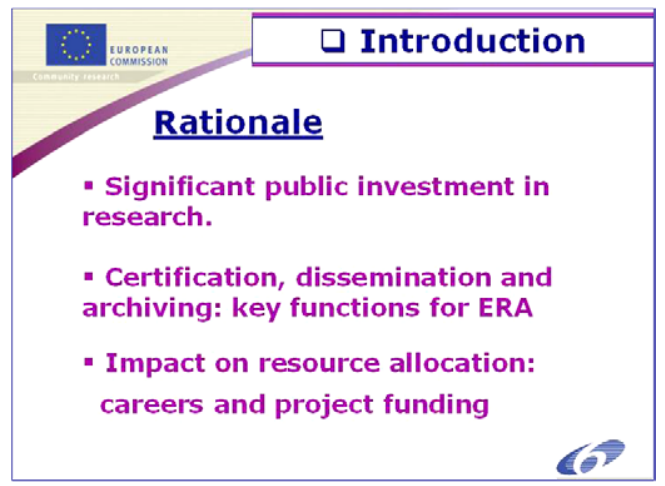

Mrs Dewandre emphasised the crucial role of academic publishing for the 'European Research Area' (ERA). She gave three main reasons.

1. The public investment in research in Europe is more than significant. And if the objective will be reached that Europe spends 3 percent of the GDP on research, it will even be more significant. Research expenditure amounts to about 67-68 billion Euro in the EU-25, the amount the 25 Member States spent from public budget in 2004. An important return on this investment needs to be ensured. A Credit Suisse First Boston report explained that the tax payer may be paying three times for the research results: the time of scientists, the salaries for referees and the university subsidies to pay for journal subscriptions. This explains the particular attention of public funding bodies for the system of scientific publication. Their goal is to ensure optimal effectiveness of this system in the ERA. This is the main financial reason.

2. The second reason is the functional role of the system of scientific publishing. It is at the heart of the functioning of the research in Europe. There is a lot to gain from the system, such as quality management through certification and the dissemination and archiving of knowledge. Archiving in the electronic age is not merely left to the network of libraries, but is being taken up by publishers and some public/private organisations as well. The system of scientific publishing acts as an indispensable filter and organisers of scientific information.

3. The third reason is a consequence of the role of certifier that peer review journals have. These publications have an impact on the allocation of research funds and they influence the careers of researchers in an important way. Research positions are offered to researchers who publish in journals of high esteem. The levels of project funding and even institutional rankings are affected as well.

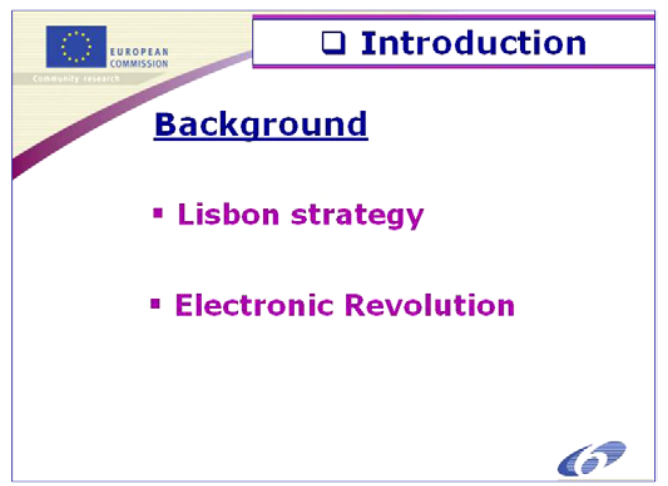


So scientific publishing has a very, very important central place in the research system.

As research has a central role in the Lisbon strategy, the pressure on research to be efficient and effective in delivering societal benefits is high. The Lisbon strategy does not only mean more money for research but also more results from research and more societal impact.

The electronic revolution and the impact of ICT on academic publishing in particular, is another important factor that needs to be considered carefully. ICT changed and still changes economic and organisational conditions in the whole society. Efficiency, effectiveness, dissemination of research results and knowledge cannot be optimal without exploiting the full potential of these technologies. For this reason this issue had a shared central place in the study that will be discussed.

\section{Aims of the study}

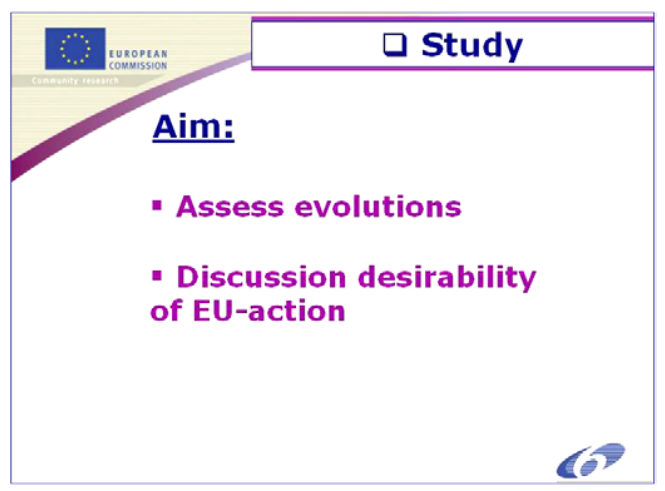

The study to be discussed has been executed by the University Libre de Bruxelles in partnership with the University of Toulouse. The lead person of the project team is Mathias de Wadripont. Several conference participants had been in contact with the researchers in the course of their study. E-Copies of the study report can be obtained from the website. Printed copies you can be requested by sending an e-mail to the address nicole.dewandre@cec.eu.int.

The study had two aims. One was to assess the economical and technological evolution of the market for scientific publishing. And the second was to discuss the desirability of measures at the European level, based on the analysis.

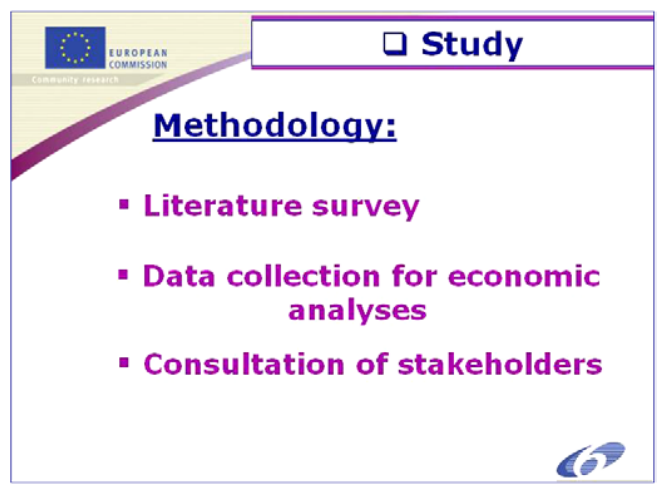


The study relies on three types of input: existing literature, data collection for economic analyses and consultation of stakeholders. It was not planned to present the study itself as this was the responsibility of the authors of the report in the first place. However, Mrs Dewandre intended to show you how the European Commission understood the main results of the study.

\section{How the Commission interprets the outcome of the study}

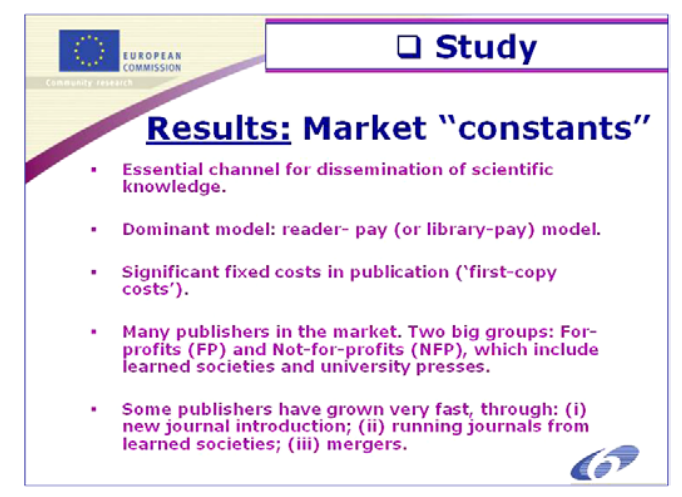

Two facts about the publishing market were emphasised in the analytical part of the report:

- The results of the quantitative investigation of journal prices, and

- The impact of the electronic revolution.

After a discussion of the two issues, the recommendations were to be discussed.

The first observation is that scientific journals are increasingly an essential channel for dissemination of scientific knowledge. The market and the publishing houses have grown with the growth of the research 'production'. The dominant business model remains the reader/library-pay model. The authors pointed out that the market is characterized by several market imperfections. Imperfections, not in a normative sense, but in the economic terminology. It is an intermediated market; the contract is between publishers and libraries and not between authors and readers. This leads to low reader price sensitivity. Further, journals are not substitutes for each other but are complementary because readers want to have a wide range of journals at their disposal.

So the situation is very different from what economists call a perfectly competitive situation. They also point to the fact that there are significant fixed costs (first-copy costs) and low dissemination costs (even much lower with the electronic revolution). Most publishers can be classified as either for-profit (FP) or not-for-profit (NFP). NFP publishers include learned societies and university presses. There has been a rapid growth, recently of some FP publishers, mainly because of new journal introductions, the running of journals for learned societies and mergers.

An accelerated upward price evolution took place in the period 1975-95. Prices of journals increased 200 to $300 \%$ beyond inflation.

Many librarians have come to the Commission to complain about this situation that was putting their budgets under high pressure. The price increases were accompanied by a lowering of the number of subscriptions, especially by individual researchers but also by libraries. Some concluded that the increase of the price was a result of the fall of the subscriptions, but this seems a typical chicken and egg problem. 

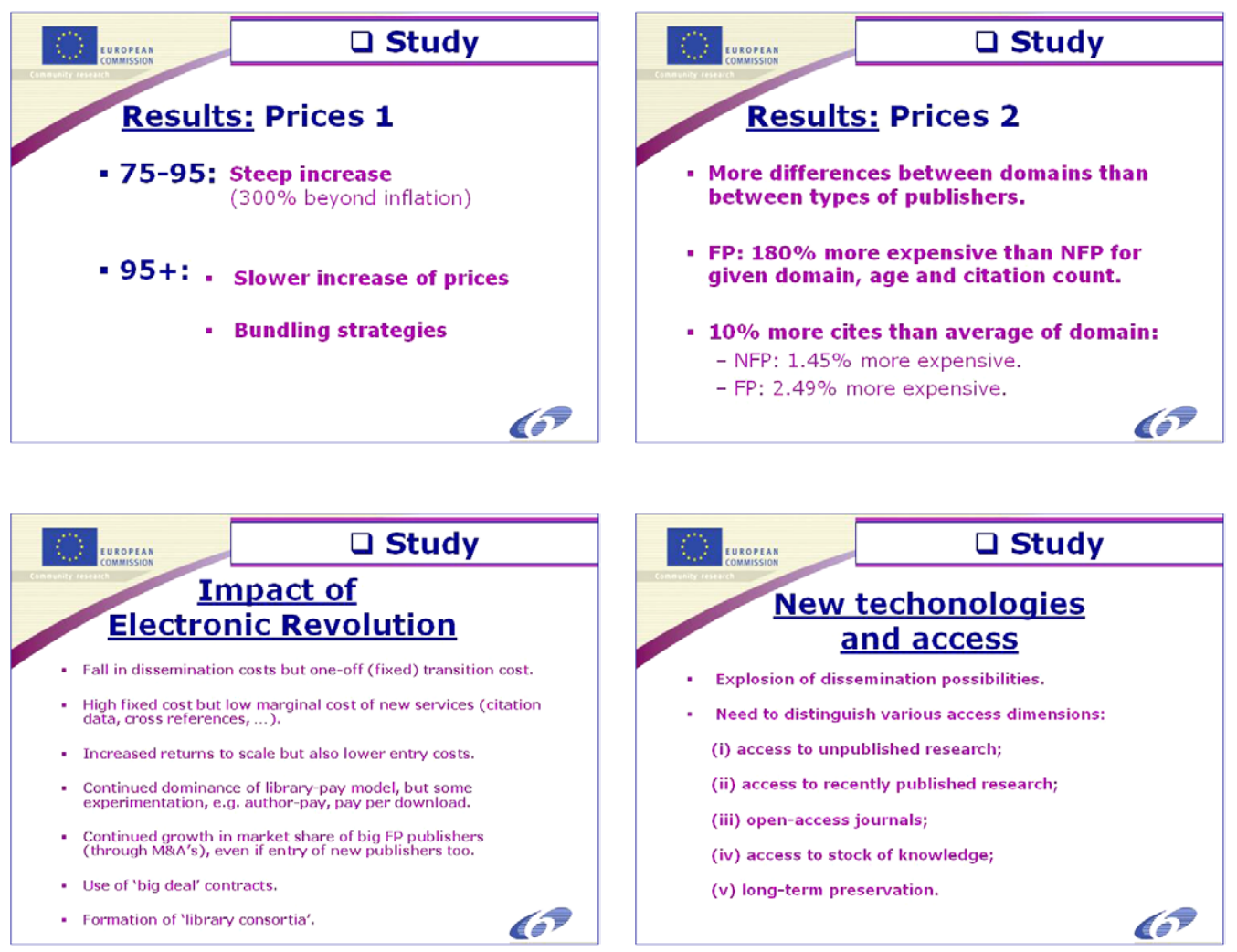

After the electronic revolution which started effectively in 1995, the price increase slowed down but was still beyond inflation. Bundling strategies appeared. The researchers did an economic data analysis to check whether the price increases were value-based or cost-based. They found that the FP publishers tend to be more expensive than NFP publishers for a given domain, age and citation count. Both the NFP and FP journals tend to be more expensive when they are cited more frequently. So the study concludes that this shows that pricing is value-based rather than cost-based. And they call the attention of the sector actors for unjustified price increases.

The impact of the electronic revolution is the second main factor analysed in the study. The comprehensive and systematic presentation of the organisational and economic effects of the introduction of ICT in the sector was very useful, according to Mrs Dewandre. The introduction of ICT caused a sharp decrease of dissemination costs but, on the other hand, a one-off fixed transition cost. High fixed but low marginal cost for new services are observed, such as for citations and data references. The dynamics of the market and the business model as known before really changed. Self archiving became possible as well as open access repositories. The functions of certification and dissemination which were bundled by the journals could now be implemented by different actors and need not necessarily to be bundled. New business model opportunities appeared and the study reports several experiments that are going on, particularly in Asia, the Pacific, South-America, Central America. Stakeholders in Europe should be encouraged to explore the new business models even more.

ICT and electronic access cause the dissemination possibilities to explode. The authors of the report suggest that certification and dissemination could be dealt with separately. And that there is a need to distinguish various access dimensions: unpublished research, and recently published research. As 
well as open-access journals from open access archives, access to stocked knowledge and long-term preservation.

\section{Recommendations of the study}
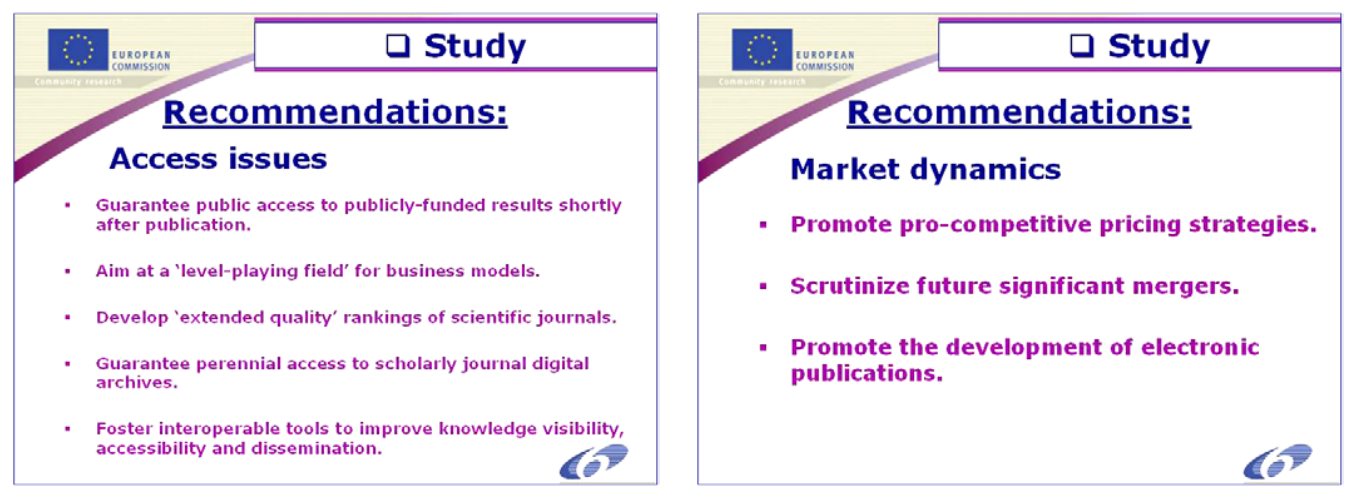

The authors recommend guaranteeing public access to publicly-funded results shortly after publication. The authors have looked at copyright policies of 116 publishers covering 8460 journals. The report states that $67 \%$ of these publishers allow authors to self-archive post prints, $4 \%$ allow self-archiving of preprints, whereas $20 \%$ do not allow any self-archiving. Publisher policies have become more permissive over time and the report calls for an increased public access to publicly funded research.

Another recommendation aims at the establishment of a level-playing field for various business models in publishing. This should benefit experimenting with new business models, such as the author-pay, the paper-download, the hybrid and the reader-pay or library-pay models. The report also suggests supporting an extension of quality rankings of scientific journals. Beyond citation frequency, other issues such as speed of publication, author friendly copyright policy, indexation and preservation should also count for the quality ranking of a journal. This would allow more competition between journals and makes the criteria for the choice in which journal an author wants to publish more transparent.

The report also recommends guaranteeing perennial access to scientific publication archives. The archiving problem is huge and as has already been recognised by the European Commission as an important aspect of the digital library initiative.

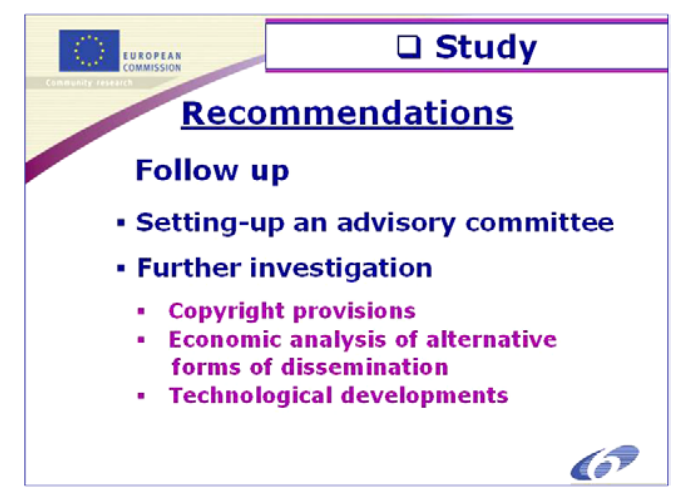




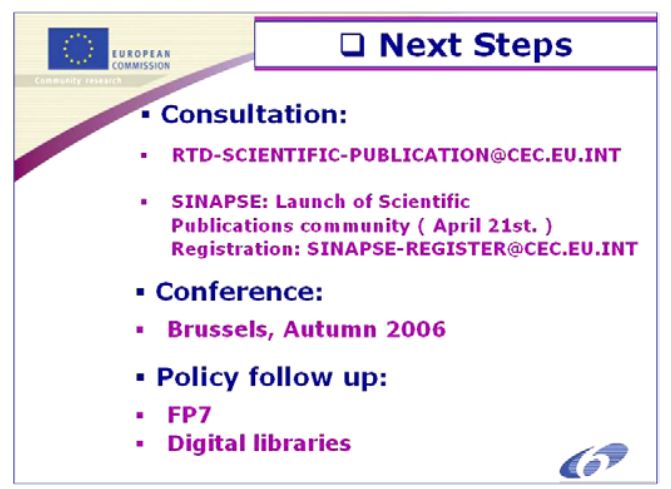

Still another recommendation calls for interoperable electronic tools to improve visibility, accessibility and dissemination. The full potential of ICT in improving the circulation of scientific information will only be realised if the tools being developed are made interoperable.

Based on their analysis of the price behaviour, the study team concludes that pro-competitive pricing strategies should be promoted. The report invites the Commission to scrutinize future significant mergers. There were many publishers in the market, but they have grown quite quickly due to mergers.

Another point concerns the promotion of electronic publications by eliminating the VAT differences for between printed and electronic publications.

Two recommendations concern the follow up of the study: the establishment of an advisory committee, and the further investigation of copyright provisions, the economic analysis of alternative forms of dissemination and the study of alternative business models. Technological developments, mainly concerned with interoperability of tools, indexing and cross referencing should also be explored further.

\section{Conclusion}

What are the plans of the Commission with this study? In the first place the reactions of the stakeholders in the ERA and beyond will be collected, analysed and synthesised. The Commission will organise a debate about scientific publishing on SINAPSE, a new web tool that aims at bringing scientific communities closer to policy makers. Stakeholders interested to participate in a more structured debate about the different recommendations are suggested to apply for access to SINAPSE. It is merely needed to send an e-mail to the SINAPSE register expressing the specific interest, after which an invitation will be issued to take part in this debate.

The Commission will organise a conference in Brussels in the autumn of 2006, probably at the end of November, early December. Any policy proposal of the Commission will be based upon these public discussions.

Several actions regarding scientific publishing may be supported and financed by the seventh European Framework Programme for Research and Development $\left(\mathrm{FP}^{3}\right)$. The Infrastructure theme of the FP7 might accept projects aimed at ensuring interoperability of archives and digital libraries. And the Science and Society theme will allow research on the evolution of business models, certification systems and extended quality ranking, mentioned earlier. These are examples; those interested to make proposals should consult the official documents, and/or contact the responsible Commission staff.

\footnotetext{
${ }^{3}$ Information about FP7: http://cordis.europa.eu/fp7/ The 50 billion $€$ programme is split into 4 major sub-programmes and a number of 'themes' as mentioned here.
} 
The Research Directorate General works closely together with the Information Society department that developed the Communication ${ }^{4}$ on Digital Libraries and another one on scientific information, both are expected to be published towards the end of 2006.

\footnotetext{
${ }^{4} \mathrm{~A}$ Communication is an official document which sets out the policy in a particular field. In some cases a Communication includes a proposed programme of action.
} 